\title{
Information processing during general anesthesia: Evidence for unconscious memory
}

\author{
A. E. BONEBAKKER \\ Psychiatric Center "Rosenburg," The Hague, The Netherlands \\ B. BONKE \\ Erasmus University, Rotterdam, The Netherlands \\ J. KLEIN \\ St. Clara Hospital, Rotterdam, The Netherlands \\ G. WOLTERS \\ University of Leiden, Leiden, The Netherlands \\ T. STIJNEN and J. PASSCHIER \\ Erasmus University, Rotterdam, The Netherlands \\ and \\ P. M. MERIKLE \\ University of Waterloo, Waterloo, Ontario, Canada
}

\begin{abstract}
Memory for words presented during general anesthesia was studied in two experiments. In Experiment 1, surgical patients $(n=80)$ undergoing elective procedures under general anesthesia were presented shortly before and during surgery with words via headphones. At the earliest convenient time after surgery (within $5 \mathrm{~h}$ ) and $24 \mathrm{~h}$ later, memory was tested by asking patients to complete auditorily presented word stems with the first word that came to mind and to leave out words they remembered having heard earlier (exclusion task). Moreover, patients were requested to perform a "yes $/ \mathrm{no}^{\text {" forced- }}$ choice recognition task to assess recognition memory for both the pre- and intraoperative words. Memory for the material presented during anesthesia was demonstrated immediately after surgery and $24 \mathrm{~h}$ later by means of both tasks. In a second similar experiment $(n=80)$, the results were replicated. These findings show that anesthetized patients can process information that was presented intraoperatively.
\end{abstract}

Over the past few years, perception and memory during general anesthesia have become major scientific topics. Both anesthesiologists and psychologists attempt to find out whether patients can perceive information presented during general anesthesia, and, if so, what the preconditions for such nonconscious cognition are. Some

This research was supported by Grant 900-559-027 from the Dutch Organization for Scientific Research (NWO) and was carried out at the Department of Medical Psychology and Psychotherapy of Erasmus University Rotterdam and at the Department of Anesthesiology of St. Clara Hospital, Rotterdam. The results of these experiments were presented at the 23rd Congress of Applied Psychology, Madrid, July 1994, and at the 3rd International Congress on Memory and Awareness in Anesthesia, Rotterdam, June 1995. The authors thank the Directory Board the Department of Anesthesiology, and the patients of St. Clara Hospital for their cooperation. The authors also thank J. G. Bovill, G. Caseley-Rondi, M. Jelicic, F. G. A. van der Meché, E. M. Reingold, J. F. Kihlstrom, D. B. Mitchell, and G. L. Wolford for their helpful comments on earlier drafts of this manuscript. B. B. is in the Department of Medical Psychology and Psychotherapy, Erasmus University; J.K. is in the Department of Thoracic Surgery, University Hospital "Dijkzigt," Rotterdam; G.W. is with the Unit of Experimental and Theoretical Psychology, Leiden; T.S. is in the Department of Epidemiology and Biostatistics, Erasmus University; J.P. is in the Department of Medical Psychology and Psychotherapy, Erasmus University; and P.M.M. is in the Department of Psychology, University of Waterloo. Correspondence should be addressed to A. E. Bonebakker, Department of Consultive Neurology and Psychology, Psychiatric Center "Rosenburg," P. O Box 53019, 2505 AA The Hague, The Netherlands (e-mail: boneklui@box.nl). studies reported that, under some circumstances, anesthetized patients can process information that was presented intraoperatively, whereas other studies yielded negative results (Bonke, Fitch, \& Millar, 1990; Ghoneim \& Block, 1993; Sebel, Bonke, \& Winograd, 1993). In other words, the whole research area is confusing due to an inconsistent pattern of results across studies (Andrade, 1995; Bonebakker, 1995).

Moreover, a reliable measure of depth of anesthesia is not yet available (although work by Munglani, Andrade, Sapsford, Baddeley, \& Jones, 1993, into particular aspects of the auditory evoked response, the "coherent frequency," is promising). No matter how adequate a certain anesthetic technique may seem, there is still no reliable way to guarantee that all the patients in a particular study have in fact completely been anesthetized for the entire duration of the operation. Consequently, evidence for memory for material presented during anesthesia can always be attributed, theoretically, to a temporarily light anesthesia. This makes it almost impossible to make any judgments about the nature (conscious or unconscious) of the memory effects found. To find out whether any effects obtained in the context of general anesthesia can be 
interpreted as purely unconscious, attention should be paid to the best possible assessment of anesthetic depth. In a series of subliminal-perception experiments, Merikle and Joordens (1996) demonstrated that "exclusion instructions" (Debner \& Jacoby, 1994; Jacoby, 1991; Jacoby, Toth, \& Yonelinas, 1993) can be used to measure conscious and unconscious contributions to memory performance. The distinguishing characteristic of these instructions is that subjects are instructed not to use particular responses when performing a specific memory task. The rationale is that if subjects can follow these instructions (i.e., if they are able to exclude particular responses), there is evidence for conscious control. In contrast, if they fail to follow the instructions (i.e., still come up with these particular responses), there is evidence for unconscious processes. In the experiments described in this article, exclusion instructions were applied by including both preoperative and intraoperative presentations of words in the experimental design. During postoperative word completion, patients were instructed to complete word stems with the first word that came to mind except the words patients remembered having heard earlier (either before or during anesthesia). The critical hypothesis here was that patients would be able to exclude preoperatively presented words, which they would recall, but would fail to exclude words presented during anesthesia, of which they would have no conscious recall. Such an outcome would provide evidence for unconscious memory for the intraoperative words. In contrast, if patients performed either below or at baseline level on the intraoperative words, this would mean that they had either conscious memory or no memory at all, respectively, of material presented during anesthesia (see also Merikle \& Joordens, 1996).

Since adequate general anesthesia impairs conscious memory processes, it is logical to assume that intraoperatively presented material will not be recognized postoperatively. Indeed, this is what some investigators who used traditional direct memory tasks, such as free recall and unforced recognition, have found (Browne \& Catton, 1973; Cork, Kihlstrom, \& Schacter, 1993; Kihlstrom, Schacter, Cork, Hurt, \& Behr, 1990; Villemure, Plourde, Lussier, \& Normandin, 1993). Kihlstrom and Schacter (1990) predicted that recognition tasks might show sensitivity to unconscious memory. Caseley-Rondi, Merikle, and Bowers (1994), in fact, found that their forced-choice recognition tasks showed sensitivity to information presented during general anesthesia. In addition, Dorfman, Kihlstrom, Cork, and Mislaszek (1995) demonstrated intact recognition in amnesia following electroconvulsive therapy, using a high-criterion recognition test. Inspired by these findings and the assumptions made by Kihlstrom and Schacter (1990), we reasoned that if subjects are requested to respond to every item in a recognition task (even if unsure), their answers may be based on unconsciously perceived material. In other words, (forcedchoice) recognition tasks may reveal memory for information presented during general anesthesia (Block, Ghoneim,
Sum Ping, \& Ali, 1991; Caseley-Rondi et al., 1994; Dorfman et al., 1995; Evans \& Richardson, 1988; Kihlstrom \& Schacter, 1990; Millar \& Watkinson, 1983). Therefore, we assessed memory for words presented during general anesthesia by a forced-choice "yes/no" recognition task, in addition to a word-stem completion task.

The central issue of the present experiments was to determine whether there is memory for words presented during general anesthesia and whether it can be assessed by means of two different memory tasks (i.e., word-stem completion and forced-choice recognition). Moreover, exclusion instructions were employed to assess the nature of memory processes underlying memory during general anesthesia. Finally, the interval between presentation of stimuli and postoperative memory test and the number of stimulus presentations were manipulated in order to determine some of the experimental circumstances under which memory during anesthesia occurs (see also Andrade, 1995; Bonebakker, 1995; Ghoneim \& Block, 1993). In both experiments, standardized anesthetic techniques were employed, and comparable subject samples were studied

\section{EXPERIMENT 1}

As described in the introduction, the main goal of the present experiments was to assess memory during general anesthesia with a specific experimental procedure. Moreover, two experimental variables were manipulated to determine their effect on unconscious memory. Thus, in Experiment 1, the duration of memory for material presented during anesthesia was studied by testing patients at two different moments-immediately after surgery and $24 \mathrm{~h}$ later. Recent studies have demonstrated memory effects when patients were tested immediately (within 3-5 h) after surgery (Jelicic, Bonke, Wolters, \& Phaf, 1992; Roorda-Hrdlicková, Wolters, Bonke, \& Phaf, 1990) and as late as 5 days (Schwender, Kaiser, Klasing, Peter, \& Pöppel, 1994) or 2 weeks (Cork et al., 1993) after surgery. On the basis of these findings, we expected to find evidence of memory for the presented words at both delays.

\section{Method}

Subjects. Eighty informed and consenting patients (ASA 1 or 2) ${ }^{1}$ of St. Clara's Hospital, Rotterdam, scheduled for elective surgical procedures under general anesthesia with an expected duration of 40-240 min, participated in the experiment. There were 66 women (mean age $=39.4$ years, range $=18-66$ years) and 14 men (mean age $=35.5$ years, range $=26-55$ years), who met the following criteria: fluent in Dutch, no hearing impairment, no alcohol or psychoactive drug abuse, and no known psychiatric or memory disorder. The study had been approved by the local medical ethics committee. Gynecological surgery was performed in $31 \%$ of the patients ( 25 women), plastic or reconstructive surgery in $30 \%$ (23 women, $1 \mathrm{man}$ ), general or trauma surgery in $20 \%$ ( 12 women, 4 men), neurosurgery (peripheral) in $13 \%$ ( 6 men, 4 women), and orthopedic surgery in $6 \%$ ( 3 men, 2 women).

Normative study. Before the actual experiment, normative material for the word-completion task was collected among representative surgical patients. This material was collected among patients 
who had just undergone a surgical procedure under general anesthesia in order to arrive at a set of stimuli obtained under exactly the same circumstances as those in the actual experiment (see also Bonebakker, 1995). After medical ethics approval, 41 informed and consenting patients $(30$ women and 11 men; mean age $=37.2$ years, range $=18-60$ years) were exposed to a neutral sound, via headphones, during different surgical procedures (i.e., gynecological, plastic or reconstructive surgery, orthopedic surgery, general surgery, and neurosurgery). Within 1-24 h after surgery, 42 different word stems (the first two or three letters of selected words) were presented auditorily to these patients, accompanied by the instruction to complete each word stem with the first word that came to mind. Thus, a set of spontaneous completion frequencies for these word stems was obtained.

Ad hoc, we tested the representativeness of this set by comparing completion frequencies of this set and completion frequencies of word stems used in Experiments 1 and 2. For each word stem, baseline performance on the word-completion task was compared with the completion frequency of the same item in the normative study. These comparisons yielded no significant differences in completion frequencies between the data sets.

Materials. From this normative set, 24 familiar words with different spontaneous completion frequencies (ranging from $3 \%$ to $37 \%$; proportions, .03-.37) of patients having mentioned the word in the normative study, median $=17 \%$ ) were selected for the actual experiment. For the word-completion task, four different lists of six target words (Lists 1, 2,3, and 4) were constructed. These lists were tape-recorded onto four audiotapes (Tapes A, B, C, and D), as follows. On each tape, a different combination of two lists was recorded in a crossover fashion. Tape A contained Lists 1 and 2 , Tape B contained lists 2 and 1, Tape C contained Lists 3 and 4, and Tape D contained Lists 4 and 3 , in that order (see Table 1).

The first list of words on each tape was recorded five times, with a silent 20 -sec interval between each presented list. The words in this first list were to serve as preoperative stimuli. The second list of words on each tape was recorded 30 times, with a 20 -sec interval between each presented list; this interval was filled with a neutral sound (i.e., bird sounds). The words in this second list were to be presented during general anesthesia. All tapes contained a 2.5 min presentation of the preoperative words $(5 \times 10 \mathrm{sec}$ and $6 \times$ $20 \mathrm{sec}$ ) and a $17.1-\mathrm{min}$ presentation of the intraoperative words ( 30 $\times 10 \mathrm{sec}$ and $31 \times 20 \mathrm{sec}$ ). Within each list, the six target words were presented at a speed of one word every $1.5 \mathrm{sec}$, introduced by the phrase, "Please, listen carefully ..." All words were recorded in the female voice of the experimenter. The four tapes were visually identical and had been coded by someone not involved in the experiment to maintain the double-blind character of the study.

For postoperative word-stem completion, word stems corresponding with all target words were randomly dispersed over four new lists and were tape-recorded onto four tapes. Each new list contained nine word stems: three corresponding with preoperative target words, three with intraoperative target words, and three with distractor words. Completion performance on the latter items would reflect

Table 1

Experimental Design

\begin{tabular}{lllll}
\hline & \multicolumn{4}{c}{ Tape } \\
\cline { 2 - 5 } & A & B & C & D \\
\hline Preoperative (5 times) & 1 & 2 & 3 & 4 \\
Intraoperative (30 times) & 2 & 1 & 4 & 3 \\
Postoperative & & & & \\
$\quad$ Day 1 & P & Q & X & Y \\
Day 2 & Q & P & Y & X \\
& Recognition task & & \\
\hline
\end{tabular}

Note-Pre- and intraoperative tapes $=\mathrm{A}, \mathrm{B}, \mathrm{C}$, and D. Word lists $=1$, 2,3 , and 4. Postoperative tapes $=\mathrm{P}, \mathrm{Q}, \mathrm{X}$, and $\mathrm{Y}$. Recognition task was only one tape. baseline performance (comparable with the normative data). The tapes were visually identical and coded $\mathrm{P}, \mathrm{Q}, \mathrm{X}$, and $\mathrm{Y}$ by someone not involved in the experiment. Each test tape contained a $1.45-\mathrm{min}$ presentation of nine word stems in the female voice of the experimenter, with a $10-\mathrm{sec}$ interval between each word stem. Table 1 gives an overview of the experimental design.

Finally, all 24 complete words (see Materials section) were randomly dispersed over one list, which was to serve as the postoperative recognition task. Due to the within-subjects design, some of the words in this list were target words for half the patients and distractor words for the other half, and vice versa. The list contained 12 distractor words for each patient. Six of these items were words of which the corresponding word stems had also been used in the word-stem lists. These distractors were called "old" distractors. The remaining six distractor words were "new" distractors (i.e., distractor words of which the corresponding word stems had not been used as items in the word-stem completion task). The whole list was recorded onto a cassette tape, which contained a 4.35 -min presentation of the 24 words in the female voice of the experimenter, with a 10 -sec interval between each word. Not until all data were collected were the codes of the tapes broken.

Procedure. Each patient completed the state version of the State-Trait Anxiety Inventory (Spielberger, Gorsuch, \& Lushene, 1970 ) in the afternoon before surgery to assess preoperative anxiety. If required, benzodiazepine tranquillizers were given the night before surgery ( 28 patients, $35 \%$ ). Premedication was with atropine $(0.5 \mathrm{mg}$, i.m.) $30 \mathrm{~min}$ before the operation.

All patients underwent a standardized, inhalational anesthesia. This commonly employed technique in anesthetic practice entails the administration of a hypnotic (nitrous oxide in oxygen) in combination with a volatile agent (isoflurane), an analgesic (sufentanil), and a neuromuscular relaxant (vecuronium). Induction of anesthesia was with sufentanil $(0.5 \mu \mathrm{g} / \mathrm{kg})$, vecuronium $(0.1 \mathrm{mg} / \mathrm{kg})$, and thiopentone $(5-7 \mathrm{mg} / \mathrm{kg})$. When consciousness was lost, the trachea was intubated. Anesthesia was maintained with nitrous oxide in oxygen (2:1) and isoflurane $0.25-0.5 \mathrm{vol} \%$. End-tidal concentrations of isoflurane were continuously maintained at $0.2-0.4$ $\mathrm{MAC}^{2}$ (expired); incremental doses of sufentanil and vecuronium were administered every $30 \mathrm{~min}$ and when needed. The lungs were mechanically ventilated. At the end of the operation, neostigmine combined with atropine was given for reversal of residual muscular relaxation, and the isoflurane and nitrous oxide administration was discontinued. As soon as patients responded adequately to instructions and breathed spontaneously, the trachea was extubated.

The patients were randomly (by means of a random list) assigned to one of the four tapes in a double-blind fashion: Tape A (19 patients), Tape B (24 patients), Tape C (14 patients), and Tape D (23 patients). To control for possible effects of type of surgery and age, the patients were stratified over three age groups (18-35, 36-50, and 51-65 years) and three levels of expected pain stimulation during surgery (on the basis of the location of surgery and the relative impact and intensity of the operation as assessed by the attending anesthesiologist). Patients who received Tape A or Tape B were tested with the corresponding postoperative Tapes $\mathrm{P}$ and $\mathrm{Q}$, and those assigned Tape $C$ or Tape D were tested with the corresponding Tapes $X$ and $Y$ (see Table 1).

About $15 \mathrm{~min}$ before induction of anesthesia, the patients were visited by the experimenter and asked to listen to a tape (A, B, C, or D) with a list of six words, via headphones and a Sony WM-EX 70 Walkman. They were instructed not to learn the words by heart and, to maintain the double-blind character of the experiment, not to discuss the contents of the tape with the experimenter or anyone else. This lasted about $5 \mathrm{~min}$. As soon as the preparations for surgery were finished, the headphones were put into position and the patients' ears were covered with a towel. This prevented both the patients from hearing sounds from the operating room and the experimenter from hearing the contents of the tape. Then, from about 15 min after induction of anesthesia, all patients were played the 
neutral sound (birds) via headphones. Five minutes after the first incision, the experimental tape (A, B, C, or D) was restarted, and, after approximately $15.30 \mathrm{~min}$, bird sounds were again played to all patients for the rest of the operation.

In 68 patients, the first postoperative test session took place within $4 \mathrm{~h}$ after surgery. The mean interval between the end of surgery and the first postoperative test was $2 \mathrm{~h} 6 \mathrm{~min}$ (range $=35-300 \mathrm{~min}$ ). Twelve patients were too ill to answer any questions on the day of surgery and were tested as soon as possible the morning after surgery. The mean interval between the end of surgery and their first postoperative test was $17 \mathrm{~h} 40 \mathrm{~min}$ (range $=17 \mathrm{~h} 10 \mathrm{~min}$ to $20 \mathrm{~h} 45 \mathrm{~min}$ )

The patients were interviewed about explicit recall of both preand intraoperative events, with the following questions: "What do you remember about the period before the anesthesiologist came?" "What is the last thing you remember before you were put to sleep for your operation?" "Did you hear anything during the operation?" and "Did you dream of anything during the operation?" The firs postoperative tape was then played. The order in which Tapes $P$ and $Q$ or Tapes $X$ and $Y$ were presented on Days 1 and 2 was randomized. The subjects were asked to verbally complete the nine word stems with the first word that came to mind. For the exclusion task, they were specifically instructed not to complete the stems with words they remembered having heard earlier either before or during anesthesia. They were asked to name any other word that came to mind in such cases. In order to investigate whether the patients had understood and followed the exclusion instructions, they were asked after the test if they had deliberately excluded particular words. This session lasted 5-10 min. The same instructions were given at the word-completion session on Day 2, approximately $24 \mathrm{~h}$ after surgery, for the second postoperative tape.

Finally ( $24 \mathrm{~h}$ postoperatively), the tape for the recognition task was played. The 24 complete words were presented via headphones, and the patients were instructed to decide, for each word, whether it was a previously presented word or not (i.e., forced-choice yes/no recognition task). The subjects were encouraged to take their time and to do their best to remember if they had heard the words before, either right before or during the anesthesia. We encouraged them to guess in cases in which they were not sure. When the test was finished, the patients were asked how confident they were about their responses. The experimenter was aware of the order in which the words were presented on the recognition tape but not of the particular contents of the pre- and intraoperative tapes. This session lasted about $15 \mathrm{~min}$

Any target words named were scored as hits; distractor words were scored as false positives. All patients could thus obtain a maximum of three preoperative and three intraoperative hits and three false positives in both word-completion sessions (Days 1 and 2) and a maximum of six preoperative and six intraoperative hits and 12 false positives in the recognition task.

\section{Results and Discussion}

To study word-completion performance across the two delays, a multivariate analysis of variance (MANOVA, repeated measures) was applied to the data of the wordcompletion task with the factors condition (preoperative, intraoperative, distractor words), tape (A, B, C, D), and day (Day 1, Day 2). The data of the forced-choice recognition task were analyzed by means of an ANOVA with the factors condition and tape. We used the $5 \mathrm{~V}$ module of the BMDP statistical package to perform the ANOVA. The limit of statistical significance was $p=.05$ (two-tailed).

Free recall. All patients remembered the preoperative presentation of words and the intravenous administration of the anesthetics for induction. None had any recall of the intraoperative period.
Word completion. The 12 patients for whom immediate testing was not possible (see Procedure section) were tested the morning after surgery. Because we did not want to loose the data of this group, their scores on the first completion session were included in the analysis and treated as scores on Day 1.

Table 2 shows the mean proportions of hits on preoperative and intraoperative items and of false positives (baseline performance) for word completion. Overall, there were no significant interactions between condition, tape, and day. No significant main effects of tape and day were found, indicating that there was no difference in performance across tapes or days. A significant main effect of condition was found $\left(\chi^{2}=7.05, d f=2, p=.03\right)$, indicating significant differences in performance across the three conditions. We then compared numbers of hits or baseline performance in the three conditions pairwise: (1) intraoperative with baseline, (2) preoperative with baseline, and (3) preoperative with intraoperative. These comparisons revealed the following results: (1) A main effect of condition $\left(\chi^{2}=7.43, d f=1, p=.006\right)$, indicating that the patients were more likely to complete word stems with words presented during anesthesia than with distractor words. This finding indicates memory for the words presented during anesthesia. (2) No main effect of condition (i.e., no significant difference in performance on preoperative items relative to baseline performance). In other words, the patients did not exclude all preoperative words (if they had, then the preoperative hit ratio would have been below baseline). (3) No main effect of condition, which contradicts our hypothesis that the patients would exclude more preoperatively presented words than intraoperatively presented words.

Recognition. As described above in the Materials section, the recognition task items contained old and new distractors. Old distractors were words of which the corresponding word stems had been used as items in the word-completion task. New distractors were words of which the word stems had not been presented before. Mean numbers of false positives on old and new distractors were 0.67 and 0.68 , respectively. This indicates that, where the distractors were concerned, there was no advantage of previously presented word stems.

Table 2

Mean Proportions and Standard Deviations of Hits/False Positives on Word Completion and Recognition

\begin{tabular}{|c|c|c|c|c|c|c|}
\hline & \multicolumn{6}{|c|}{ Condition } \\
\hline & \multicolumn{2}{|c|}{ Preoperative } & \multicolumn{2}{|c|}{ Intraoperative } & \multicolumn{2}{|c|}{ Distractor } \\
\hline & $M$ & $S D$ & $M$ & $S D$ & $M$ & $S D$ \\
\hline \multicolumn{7}{|c|}{ Word Completion } \\
\hline Day 1 & 0.19 & \pm 0.22 & 0.23 & \pm 0.25 & 0.14 & \pm 0.21 \\
\hline Day 2 & 0.16 & \pm 0.19 & 0.21 & \pm 0.23 & 0.15 & \pm 0.21 \\
\hline \multicolumn{7}{|c|}{ Recognition } \\
\hline Day 2 & 0.75 & \pm 0.24 & 0.20 & \pm 0.20 & 0.11 & \pm 0.19 \\
\hline
\end{tabular}

Note - Proportions are the number of hits or false positives divided by the maximum number of hits or false positives that could be obtained (during a particular test session). 
No interaction was found between condition and tape, indicating that memory performance did not differ across tapes. As expected, the main effect of condition was significant $\left(\chi^{2}=481.46, d f=2, p<.001\right)$, indicating that performance differed across the three conditions. Numbers of hits and false positives were then compared between conditions, which showed that the patients recognized considerably more intraoperatively presented target words than distractors $\left(\chi^{2}=14.94, d f=1, p<\right.$ $.001)$. Sixty percent of the words that were designated "recognized" and that had been presented during anesthesia were words that had not come up as completions in the completion test (new hits). Mean numbers of old and new hits were 0.48 and 0.70 , respectively. This reflects spontaneous, unbiased recognition for the majority of the intraoperative words. The patients reported that, in general, they were not very confident about their guesses during the recognition task.

As expected, comparison of recognition performance on the preoperative words with that on intraoperative words showed that the patients recognized considerably more preoperative words than intraoperative words $\left(\chi^{2}=\right.$ $181.74, d f=1, p<.001)$. Note that not all preoperative words were recognized.

Other variables. Mean preoperative anxiety was 43.6 and, hence, was slightly elevated. There was no relation between hit scores on the word-completion task and the recognition task, on the one hand, and preoperative anxiety or estimated pain intensity, on the other. The same applied to age and gender.

Exclusion instructions were used in the word-completion task to find out whether memory for material presented during anesthesia can be regarded as unconscious. We assumed that the patients would have conscious memory for the preoperative words and consequently exclude those words. The results show a different pattern: performance on the preoperative items did not differ from baseline performance, indicating that memory for the preoperative words was not perfect. In retrospect, this is perhaps not surprising if one takes into account the anxiety and stress that patients experience shortly before surgery. It seems likely that this affects patients' concentration. Moreover, the patients were not specifically instructed to remember the words presented before surgery in order to match the pre- and intraoperative situations with respect to the passive condition of the patients. Although the words had been repeated five times to promote learning, some were nevertheless forgotten.

Likewise, we expected that the patients would have unconscious memory for the words presented during anesthesia and, consequently, fail to exclude these words on the word-completion task. Performance on the intraoperative items was in accordance with these expectations: the number of failures to exclude was significantly greater than baseline level, which indicates unconscious memory (see also Merikle \& Joordens, 1996). In sum, our findings suggest that unconscious memory was more dominant than conscious memory for both preoperative and intraoperative material.
The most striking outcome of Experiment 1 is the demonstration of memory for intraoperative material by means of a forced-choice recognition task. Our findings contradict previous results (Block et al., 1991; Dubovsky \& Trustman, 1976; Parker, Oates, Boyd, \& Thomas, 1994) and support the idea that forced-choice recognition is sensitive to material presented during general anesthesia (Caseley-Rondi et al., 1994; Evans \& Richardson, 1988; Kihlstrom \& Schacter, 1990; Millar \& Watkinson, 1983). The nature of the instructions (unforced vs. forced) at test may explain the "success" of this task: if patients are instructed to respond to each item, guessing behavior is increased, and, apparently, patients tend to be quite accurate in their guesses. On the other hand, if patients are allowed not to respond if unsure or, in other words, are not specifically encouraged to guess, (unconscious) information that may contribute to correct responses may be suppressed. In our experiment, the inclusion of preoperative words (i.e., words that patients could easily recognize) may have increased the patients' confidence so that they were more prone to say "yes" to intraoperative words on the basis of vague feelings of familiarity (Kihlstrom \& Schacter, 1990). Mandler (1980) and Kihlstrom and Schacter (1990) suggested that the recognition of a previously presented item is partly based on feelings of familiarity. In Mandler's view, two simultaneous processes are invoked when a subject has to recognize an item. The first process indeed retrieves the familiarity value of the item, and the second mechanism engages in a search and retrieval process that attempts to determine whether the target item was originally presented. These processes are assumed to operate independently of each other. Mandler's recognition memory model helps explain our recognition task results because it distinguishes between remembering that is initiated and guided by a conscious intention versus remembering guided by feelings of familiarity. As stated earlier, it seems likely that the patients in our experiment made the decisions about previous presentation of the intraoperative words on the basis of feelings of familiarity, but we have no empirical data to support this (see also Dorfman et al., 1995).

With regard to the duration of the memory effects, the present experiment yields evidence for unconscious memory immediately after surgery and $24 \mathrm{~h}$ later, indicating that these memory effects last at least $24 \mathrm{~h}$. On the basis of several negative findings, we have argued that implicit memory during anesthesia is an elusive, transient phenomenon (Bonebakker, Bonke, Klein, Wolters, \& Hop, 1993). However, the results of a study by Kihlstrom et al. (1990) indicate that implicit memory in anesthesia may be preserved for 2 weeks. The study by Schwender et al. (1994), who found memory effects after 3-5 days postoperatively, and the present evidence for unconscious memory after $24 \mathrm{~h}$ demonstrate that these effects can be long lasting. The intraoperative presentation of words results in the activation of their representations in memory (Graf \& Mandler, 1984). These representations can remain activated for a certain period of time, resulting in the demonstration of unconscious memory after a 24 -h delay. 


\section{EXPERIMENT 2}

The first research question of Experiment 2 was, "Is there any memory for intraoperatively presented words?" thus trying to replicate the findings in Experiment 1 with the same experimental procedure. Since the demonstration of preserved recognition memory is relatively new, we reasoned that a replication of our findings would be in order.

To study the role of number of presentations, the second research question was, "Does memory for words presented once differ from memory for words presented 30 times?" In most anesthesia studies, multiple presentations of stimuli have been used. Consequently, it is still unclear whether a single presentation of a stimulus is sufficient to cause a memory effect. Experiments in which the number of presentations was manipulated did not yield a clear picture. Winograd, Sebel, Goldman, and Clifton (1990) and Bonebakker et al. (1993) varied the number of stimulus presentations but failed to find any memory effects. Block et al. (1991) found that nonsense words that had been presented frequently (at maximum 16 times) were preferred more on a postoperative preference task than were words presented less frequently, but this was not replicated in additional control tests. In the present experiment, number of stimulus presentations was varied by presenting words 1 or 30 times during anesthesia. To study the possibility that words presented once are "overruled" during intraoperative presentation by words presented 30 times, we added an experimental condition in which all words were only presented once (see also Brown, Best, Mitchell, \& Haggard, 1992).

\section{Method}

Subjects. Eighty informed and consenting patients (ASA 1 or 2 ), scheduled for elective surgical procedures under standardized, general anesthesia with an expected duration of $40-240 \mathrm{~min}$, participated in the experiment. There were 52 women (mean age $=39.8$ years, range $=18-64$ years) and 28 men (mean age $=40.6$ years, range $=23-63$ years). See also Experiment 1 Method section for exclusion criteria.

Neurosurgery (peripheral) was performed in $30 \%$ of the patients ( 9 women, 15 men), general or trauma surgery in $26 \%$ ( 14 women, 7 men), plastic or reconstructive in $20 \%$ ( 14 women, 2 men), orthopedic in $17 \%$ ( 10 women, 4 men), urological in $4 \%$ ( 3 women $)$, and gynecological in 3\% ( 2 women).

Materials. The critical set of stimulus words was the same as that used in Experiment 1. Four different lists (Lists 1-4) of six target words were constructed. The lists were tape-recorded onto four audiotapes (Tapes A-D), counterbalanced in different combinations (Table 3). Words not recorded on a particular tape (e.g., List 4 for Tape A) were to serve as distractor words on the postoperative tests (i.e., performance on these items would reflect baseline performance).

The first six words on each tape, which were to serve as the preoperative stimuli, were recorded with a 15 -sec interval, filled with silence, between each word. On Tapes A, C, and D, the second list of words was recorded once and the third list was recorded 30 times. These words were to be presented during general anesthesia. Between each presented list, there was an interval of $20 \mathrm{sec}$, filled with a neutral filler sound (bird sounds). Each tape contained a $1.54-\mathrm{min}$ $(7 \times 15 \mathrm{sec}$ and $6 \times 1.5 \mathrm{sec})$ presentation of the preoperative words, and a $15.50-\mathrm{min}(31 \times 10 \mathrm{sec}$ and $32 \times 20 \mathrm{sec})$ presentation of the intraoperative words. On Tape B, the second and the third lists were
Table 3

Experimental Design

\begin{tabular}{lllll}
\hline & \multicolumn{4}{c}{ Tape } \\
\cline { 2 - 5 } & A & B & C & D \\
\hline Preoperative (1 time) & 1 & 2 & 3 & 4 \\
Intraoperative (1 time) & 3 & 4 & 2 & 1 \\
Intraoperative (30 times) & 2 & $1^{*}$ & 4 & 3 \\
Postoperative & & & \\
$\quad$ Day 1 & Word completion \\
Day 2 & Forced-choice recognition \\
\hline
\end{tabular}

Note-Pre- and intraoperative tapes = A, B, C, and D. Word lists $=1$, 2,3 , and 4. ${ }^{*}$ List 1 on Tape $B$ was presented once instead of 30 times.

both recorded once with a 10-min interval between the first (preoperative stimuli) and second lists and a 20 -sec interval between the second and the third lists (see Table 3). These intervals were again filled with bird sounds. The Tape $B$ condition was included to study the possibility that words that had been presented once in the other conditions would be overruled by words presented 30 times during the operation. In the Tape $B$ condition, stimulus presentation lasted $1.20 \mathrm{~min}(2 \times 10 \mathrm{sec}$ and $3 \times 20 \mathrm{sec})$. The rest of this tape and the other tapes were filled with bird sounds. Each list was preceded by the phrase, "Please, listen carefully ..." To maintain the double-blind character of the experiment, the four tapes were visually identical and had been coded by someone not involved in the experiment.

For the postoperative word-completion task, a tape containing 12 word stems was prepared. For each patient, three word stems corresponded with the preoperative target words, six with the intraoperative target words (three from each intraoperative list), and three with distractor words. The duration of this tape was $2 \mathrm{~min}$.

Finally, all 24 complete target words were randomly dispersed over one list, which consisted of six preoperative target words, 12 intraoperative target words, and six distractor words for each patient. The list was tape-recorded and lasted $4.35 \mathrm{~min}$. All recordings were in the female voice of the experimenter. Not until the experiment was finished were the codes of the tapes broken.

Procedure. All patients were asked to complete the state version of the State-Trait Anxiety Inventory (Spielberger et al., 1970) on the afternoon before surgery. If required, tranquillizers were given orally the night before surgery ( 31 patients, $39 \%$ ). Premedication was with atropine $(0.5 \mathrm{mg}, \mathrm{i} . \mathrm{m}$.) approximately $30 \mathrm{~min}$ before surgery.

Anesthesia was induced with thiopentone $(4-7 \mathrm{mg} / \mathrm{kg}$ ), vecuro$\operatorname{nium}(0.1 \mathrm{mg} / \mathrm{kg})$, and sufentanil $(1-1.5 \mu \mathrm{g} / \mathrm{kg}, 76$ patients) or alfentanil (20-30 g/kg, 4 patients), depending on the type of surgery. One patient was induced with $20 \mathrm{mg}$ etomidate instead of thiopentone, because of a history of cardiac arrhythmias. Anesthesia was maintained with nitrous oxide in oxygen ( $2: 1)$, isoflurane $0.25-0.50$ vol\%, and incremental doses of vecuronium and sufentanil or alfentanil ( 4 patients) when needed. End-tidal concentrations of isoflurane were continuously maintained at $0.2-0.4 \mathrm{MAC}$, and the lungs were mechanically ventilated. Neostigmine combined with atropine was given for reversal of residual muscular relaxation at the end of the operation.

The patients were randomly assigned to one of the four tapes in a double-blind fashion: Tape A ( 25 patients), Tape B ( 23 patients), Tape C (13 patients), and Tape D (19 patients). The patients were stratified over three age groups and three levels of expected pain stimulation during surgery (see Method section of Experiment 1).

Approximately $15 \mathrm{~min}$ before induction of anesthesia, the patients were visited by the experimenter and asked to listen to a tape containing six words, via headphones. They were instructed to mentally form a sentence with each word (which may require more cognitive effort than merely listening to a word and consequently might lead to more exclusion of the preoperative words). To maintain the double-blind character of the experiment, the patients were 
asked not to mention any sentences or words to the experimenter or anyone else. This session lasted about $5 \mathrm{~min}$. Three patients were not presented with the preoperative words because the operation schedule had changed. From about $15 \mathrm{~min}$ after induction, all patients were played the neutral (bird) sounds via headphones. Five minutes after the first incision, the experimental tape (A, B, C, or D) was restarted, and, after approximately $16 \mathrm{~min}$, the tape with bird sounds was again played to all patients for the rest of the operation.

In 72 patients, the first postoperative test (Day 1) took place within $5 \mathrm{~h}$ after surgery (mean interval between end of surgery and test $=137 \mathrm{~min}$, range $=40-325 \mathrm{~min}$ ). Eight patients were too ill on the day of surgery to answer any questions and were tested the next morning, within $20 \mathrm{~h}$ after surgery. Prior to the word-completion task, the patients were interviewed about explicit recall of the preoperative and intraoperative periods (see Experiment 1). The tape with 12 word stems was then played via headphones. The patients were instructed to verbally complete each word stem with the first word that came to mind. For the exclusion task, they were explicitly instructed not to complete the stems with words they remembered having heard earlier, either before or during anesthesia. They were asked to name any other word that came to mind in such cases.

The forced-choice yes/no recognition task took place approximately $24 \mathrm{~h}$ after surgery in 73 patients: 2 patients were too ill to take the test, 2 had already been discharged from the hospital, and 3 had not heard the words presented preoperatively. The patients were presented, via headphones, with 24 complete words and were instructed to decide, for each word, whether or not it was a previously presented word. In addition, they were encouraged to take their time and to guess in cases in which they were not sure. When the test was finished, the patients were asked how confident they were about their responses. The experimenter was aware of the order in which the words were presented but not of the actual contents of Tapes A, $\mathrm{B}, \mathrm{C}$, and D. This session lasted about $15 \mathrm{~min}$.

Statistical analyses. For the postoperative tasks, words named or recognized were scored as hits if they were target words and as false positives if they were distractors. A maximum of three preoperative and six $(2 \times 3)$ intraoperative hits and three false positives could be obtained on the word-completion task. On the recognition task, a maximum of six preoperative and 12 intraoperative $(2 \times 6)$ hits and six false positives could be obtained.

To answer the first research question (i.e., "Is there any memory for intraoperatively presented words?"), the data of all patients $(N=80)$ were analyzed by means of ANOVA (using the $5 \mathrm{~V}$ module of the BMDP package) with the factors condition (preoperative, intraoperative, distractor) and tape (A, B, C, D). In order to analyze the data of all patients, the data of the one-time presentation and 30-time presentation were collapsed. Subsequently, the data of the 57 patients who had been exposed to both one and 30 presentations were analyzed to answer the second research question (i.e., "Does memory for words presented once differ from memory for words presented 30 times?") with the factors condition (intraoperative [one time], intraoperative [30 times], distractor) and tape (A, C, D). Finally, the data of the 23 patients who had been exposed to Tape $B$ (two one-time presentations) were analyzed with Student's $t$ test for paired samples.

\section{Results and Discussion}

All patients remembered the preoperative presentation of words and the intravenous administration of the anesthetics for induction. None had any recall of the intraoperative period. Both the word-completion and the forced-choice yes/no recognition task showed evidence for unconscious memory during anesthesia.

Word completion. In Experiment 1, word completion performance did not change significantly during the first $24 \mathrm{~h}$ postoperatively; therefore, the scores of the 8 pa- tients who were tested the morning after surgery were included in the analysis of the word-completion data. The mean proportions of hits and of false positives of all patients ( $N=80$, Tapes A, B, C, and D) for word completion are presented in Table 4.

Tapes $A, B, C$, and $D$. There were no significant interactions between condition and tape, indicating that no difference in performance could be demonstrated across the tapes. A significant main effect was found for condition $\left(\chi^{2}=26.04, d f=2, p<.001\right)$, indicating significant differences in performance across conditions. Pairwise comparison of the hit and false-positive ratios in the three conditions (intraoperative with baseline, preoperative with basline, and preoperative with intraoperative) revealed the following results. (1) A significant main effect of the factor condition $\left(\chi^{2}=4.26, d f=1, p=.04\right)$, indicating that the patients' performance for the intraoperative condition was significantly above baseline. This provides evidence of memory for the words that were presented during anesthesia. (2) Although the absolute number of preoperative hits was slightly below baseline (mean $=0.39$ vs. 0.43 words), there was no main effect of condition, indicating that, contrary to our expectations, the patients did not exclude all preoperative words. (3) Mean number of intraoperative hits differed significantly from that of preoperative hits $\left(\chi^{2}=22.82, d f=\right.$ $1, p<.001)$ : The patients excluded more preoperative stimulus material than intraoperative stimulus material.

Tapes $A, C$, and $D(N=57)$. Mean numbers of hits on intraoperative items presented once and 30 times were 0.71 and 0.47 , respectively; mean number of false positives was 0.38 . There was no significant interaction or main effect of tape (i.e., a difference in performance on the three item types across Tapes A, C, and D could not be demonstrated). There was, however, a significant main effect of condition ( $\left.\chi^{2}=9.88, d f=1, p=.007\right)$, indicating that performance differed between the intraoperative (one time), intraoperative (30 times), and distractor conditions. Pairwise comparisons revealed that performance on once-presented words was higher than baseline performance $\left(0.71\right.$ and 0.38 words, respectively, $\chi^{2}=$ 7.93, $d f=1, p=.004)$, whereas performance for words presented 30 times was not $(0.47$ hits vs. 0.38 false positives, n.s.).

Tape $B(N=23)$. Mean numbers of hits and false positives were $0.68,0.64$, and 0.50 for the intraoperative items

Table 4

Mean Proportions and Standard Deviations of Hits/False Positives on Word Completion and Recognition (Tapes A, B, C, and D)

\begin{tabular}{|c|c|c|c|c|c|c|}
\hline \multirow[b]{3}{*}{ Test } & \multicolumn{6}{|c|}{ Condition } \\
\hline & \multicolumn{2}{|c|}{ Preoperative } & \multicolumn{2}{|c|}{ Intraoperative } & \multicolumn{2}{|c|}{ Distractor } \\
\hline & $M$ & $S D$ & $M$ & $S D$ & $M$ & $S D$ \\
\hline Word completion & 0.13 & \pm 0.20 & 0.20 & \pm 0.19 & 0.14 & \pm 0.20 \\
\hline Recognition & 0.79 & \pm 0.17 & 0.24 & \pm 0.17 & 0.18 & \pm 0.20 \\
\hline
\end{tabular}

Note-Proportions are the number of hits or false positives divided by the maximum number of hits or false positives that could be obtained (during a particular test session). 
(Lists 1 and 4, see Experimental Design section) and the distractor items, respectively. Neither for List 1 nor for List 4 did the mean number of hits differ significantly from baseline performance. Though not significant, this pattern of results resembled the overall pattern: Mean number of hits in both intraoperative conditions was higher than that of false positives.

Recognition. The data of 73 patients (see Procedure section) were included in the ANOVA for the forcedchoice yes/no recognition task. The mean proportions of hits and false positives (Tapes A, B, C, and D) for recognition are presented in Table 4.

Tapes $A, B, C$, and $D$. There was a marginally significant condition $\times$ tape interaction $\left(\chi^{2}=12.03, d f=6\right.$, $p=.06$ ), caused by an inconsistent pattern of results across the four tapes on the distractors: Mean numbers of false positives were $0.70,1.56,1.42$, and 0.67 for Tapes $\mathrm{A}, \mathrm{B}, \mathrm{C}$, and D, respectively.

As expected, there was a significant main effect of condition $\left(\chi^{2}=426.20, d f=2, p<.001\right)$, caused mainly by the high number of recognized preoperative words $(4.75$ words) relative to recognition in the other conditions (1.41 and 1.08 words for intraoperative words and distractors, respectively).

The number of hits and false positives were compared between conditions. (1) Comparison between intraoperative hits and false positives revealed a significant condition $\times$ tape interaction $\left(\chi^{2}=11.06, d f=3, p=.01\right)$, again caused by the different false-positive ratios across the four tapes. The main effect of condition was significant ( $\left.\chi^{2}=6.27, d f=1, p=.012\right)$, indicating that more intraoperatively presented words were recognized than distractors recognized falsely. Sixty-three percent of the intraoperatively presented words that were recognized were words that had not come up as word completions during the completion task (new words). Mean numbers of hits for old words (i.e., words of which the word stems had been presented in the word-completion task) and new words were 0.79 and 1.71 (see Experiment 1). The patients reported in general that they were quite confident about their guesses. (2) As expected, comparison between preoperative hits and false positives showed a significant main effect of condition $\left(\chi^{2}=411.60, d f=1, p<.001\right)$ : The patients recognized considerably more (though not all) preoperative items than they falsely recognized distractors. (3) The same result was found for preoperative versus intraoperative hits: The patients recognized more preoperative words than intraoperative words $\left(\chi^{2}=\right.$ 294.56, $d f=1, p<.001)$.

Tapes $A, C$, and $D(N=51)$. The mean numbers of hits for words presented once and 30 times were 1.31 and 1.39 , respectively; mean number of false positives was 0.86 . An ANOVA for the data of this group yielded a significant condition $\times$ tape interaction $\left(\chi^{2}=11.38, d f=4\right.$, $p=.023$ ), indicating a difference in performance across the three conditions caused by different recognition scores on the tapes. Inspection of the data showed that this interaction effect was caused by divergent performance across Tapes A, C, and D in the intraoperative (30 times) condition: Mean numbers of hits were $1.84,1.15$, and 1.10 words for Tapes A, C, and D, respectively. The main effect of condition was significant $\left(\chi^{2}=10.34, d f=2\right.$, $p=.006)$.

Comparison of the intraoperative (one time) condition with baseline performance yielded a main effect of condition $\left(\chi^{2}=7.78, d f=1, p=.005\right)$. The patients recognized more once-presented words than distractors. Comparison of intraoperative (30 times) with baseline performance yielded a significant condition $\times$ tape interaction effect $\left(\chi^{2}=11.32, d f=2, p=.003\right.$, see previous paragraph) and a significant main effect of condition $\left(\chi^{2}=8.14\right.$, $d f=1, p=.004)$. Number of word presentations does, therefore, not have a clear effect on recognition memory $24 \mathrm{~h}$ postoperatively. There was no main effect of condition in the one-time versus 30-times comparison: Recognition after one presentation did not differ significantly from that after 30 presentations.

Tape $B(N=22)$. Mean numbers of hits and false positives were $2.05,1.05$, and 1.68 for intraoperative Lists 1 and 4 and distractors, respectively. There were no significant differences (i.e., there was no evidence of recognition memory in this subgroup). Contrary to the wordcompletion performance in this group, there was no tendency to score more intraoperative hits than false positives.

Other variables. Mean preoperative anxiety was 44.6 , which is quite elevated. There were no significant relations between memory performance, on the one hand, and preoperative anxiety, gender, age, and type of surgery, on the other.

The most important outcome of this experiment is the successful replication of the major findings in Experiment 1 . Again, memory for words presented during anesthesia was demonstrated by means of word completion and forced-choice recognition. In addition, we found an effect of number of intraoperative stimulus presentations on word-completion performance. Number of intraoperative presentations had no effect on recognition performance $24 \mathrm{~h}$ postoperatively. For word completion, memory effects occurred for the once-presented words, whereas we were unable to show such effects for the words presented 30 times. The latter result is in contrast with earlier findings (Block et al., 1991; Jelicic, Bonke, et al., 1992; Jelicic, De Roode, Bovill, \& Bonke, 1992; Roorda-Hrdlicková et al., 1990) and might suggest that in the present experiment, the patients suppressed the words that were presented 30 times. This may have happened because the patients were instructed to do so (exclusion instructions) or because they unconsciously associated the material with an aversive period in the surgical procedure (Blacher, 1993; Brown et al., 1992). The first assumption suggests that there must have been some control over the words that were presented 30 times. Some of the words may have been excluded because the patients felt they had heard the words before. The decision to exclude words that "ring a bell" could then be based 
on the same process as that underlying the recognition of intraoperative words (Kihlstrom \& Schacter, 1990): The "familiarity value" of an item is retrieved and, at the same time, a retrieval process determines whether the target item was originally presented (see also Dorfman et al., 1995; Kihlstrom \& Schacter, 1990). However, there are no empirical data at this moment to either support or invalidate the assumption that some inhibitory process affects the retrieval of information perceived during surgery.

Most recent experiments (Roorda-Hrdlicková et al., 1990; Block et al., 1991; Jelicic, Bonke, et al., 1992; Jelicic, De Roode, et al., 1992) have demonstrated memory effects after multiple presentations, suggesting that our null finding for 30 presentations is spurious. Future studies might concentrate on memory effects with different numbers of presentations throughout the course of surgery. On the basis of the present experiment, we conclude that one presentation of words is sufficient to cause a memory effect.

Exclusion instructions in the word-completion task resulted in performance below baseline on the preoperative items ( 0.39 vs. 0.43$)$, but this difference was not significant. Despite the fact that the patients were instructed to mentally form a sentence with the preoperative words in order to "force" them to pay more attention to the words and, hence, improve exclusion performance, they hardly performed below baseline. However, compared with performance in Experiment 1 ( 0.57 vs. 0.39 in the present experiment), exclusion of preoperative words was considerably better, which indicates a moderate effect of the instruction to form sentences.

\section{GENERAL DISCUSSION}

The general aim of the present experiments was to find out whether surgical patients can hear and process information during general anesthesia. The results of Experiment 2 show that the experimental procedure that was successful in Experiment 1 resulted in further evidence for memory during anesthesia. On the basis of both experiments, we suggest that presentation of words before and during inhalational anesthesia and the postoperative assessment of both conscious and unconscious memory by means of an exclusion task and a forcedchoice recognition task is a successful procedure to demonstrate memory during anesthesia. The fact that the word-completion data are nearly identical in both studies (i.e., mean baseline performance $=0.43$ in both experiments, mean number of intraoperative hits $[n=80]=$ 0.68 and 0.61 ), indicates that we are dealing with a replicable effect on word completion.

Recognition performance was somewhat different: Baseline performance and mean number of intraoperative hits were both higher in Experiment 2 than in Experiment 1 ( 1.08 vs. 0.66 false positives, and 1.41 vs. 1.20 hits). In both experiments, the patients were instructed to respond to each item on the recognition task. This "forced" character of the task stimulates subjects to guess, even if unsure, and may result in accurate guesses (CaseleyRondi et al., 1994; Dorfman et al., 1995; Kihlstrom \& Schacter, 1990). Indeed, the patients were explicitly encouraged to guess if unsure, and this may have led to a more liberal response strategy. We have argued that an essential aspect of the experimental procedure we employed is the inclusion of a preoperative presentation of words. We initially included the presentation of preoperative stimuli to validate the exclusion task. In order to demonstrate a dissociation between conscious and unconscious memory processes (which is the general idea underlying the exclusion task), memory tasks need to trigger both conscious and unconscious information in memory. In retrospect, an important side effect of the presence of familiar stimuli (i.e., items that subjects recognize) during the test phase is that the subjects' confidence may be enhanced. The results of the forced-choice recognition task help clarify this point. During this task, the patients were presented with a word list that included a number of words they would definitely recognize (i.e., the words that had been presented shortly before surgery). After this task, the majority of patients stated that they were quite confident about their answers (including the intraoperative items they had recognized). Although we have no empirical data to support this, their confidence seems to be based on the presence of words they recognized from the preoperative period: Observations in patients who had not been exposed to the preoperative words showed that they did not recognize a single item in the list.

\section{Depth of Anesthesia}

We argued that the absence of an objective measure of "depth" of anesthesia is an issue that must be addressed in each new study. In both experiments, we used the exclusion task, which is a component of the process dissociation procedure (PDP; Debner \& Jacoby, 1994; Jacoby, 1991; Jacoby et al., 1993; Toth, Reingold, \& Jacoby, 1994) to distinguish between conscious and unconscious contributions to word-completion performance (Merikle \& Joordens, 1996). PDP is a method from cognitive psychology that was developed to determine the extent to which performance on various memory tasks is mediated by conscious controlled versus automatic processes in memory. The general idea underlying the application of PDP in this context is that "adequate" anesthesia is indirectly demonstrated if we can show that unconscious rather than conscious processes underlie memory during anesthesia. Both experiments indicated influence of both conscious and unconscious influences. Exclusion performance on intraoperatively presented words indicated that unconscious influences were more dominant. However, there is not sufficient basis to rule out the possibility that memory during anesthesia was, to a certain extent, contaminated by conscious influences. Our findings merely provide us with an indication of the dominant type of memory processes, not with the exact extent of conscious and unconscious contributions to memory perfor- 
mance. In our view, future experiments need to include a condition in which all conscious influences can be separated from memory performance in the test phase. The original PDP embodies such a condition (i.e., the inclusion task). In an inclusion task, subjects are instructed to complete stems with earlier presented words and, if they are unable to do so, to complete with the first word that comes to mind. In this case, both conscious and unconscious influences act in concert because they both serve to include earlier presented words. In the exclusion task, subjects are told to complete stems with words that were not presented earlier-that is, conscious influences serve to exclude or suppress "old" words. A failure to follow the exclusion instructions reflects unconscious influences.

\section{Other Experimental Conditions}

To determine the experimental conditions under which memory in anesthesia occurs, we manipulated two other variables within each experiment. Relevant independent variables were the duration of memory effects and the number of presentations. Our results show that both variables have an effect. Experiment 1 revealed that unconscious memory effects last at least $24 \mathrm{~h}$. This finding and others (e.g., Cork et al., 1993; Schwender et al., 1994) may be starting points for further research into the duration of memory effects in anesthesia studies.

In Experiment 2, the patients were exposed to single and multiple presentations of words during anesthesia. This experiment revealed a word-completion effect after one presentation of words, but not after 30 presentations. The latter finding could not easily be explained and clearly contradicts previous studies (Block et al., 1991; Jelicic, Bonke, et al., 1992; Jelicic, De Roode, et al., 1992; RoordaHrdlicková et al., 1990) in which memory effects were demonstrated after multiple presentations. Therefore, we concluded that the absence of a word-completion effect for the words presented 30 times may be spurious. In addition, no effect of number of presentations on recognition performance after $24 \mathrm{~h}$ was found.

\section{Future Research}

Many researchers in the area have stressed the importance of getting reliable results and bringing memory in anesthesia under experimental control (Caseley-Rondi et al., 1994; Ghoneim \& Block, 1993; Kihlstrom \& Schacter, 1990; Millar, 1992). Our results indicate the existence of reliable, replicable effects. We agree with Kihlstrom and Schacter (1990) that the next step should be to get reliable results across laboratories and populations. In addition, special attention should be paid to changes in unconscious perception throughout the course of surgery. Information processing during anesthesia is a dynamic process that should be assessed accordingly.

\section{REFERENCES}

ANDRADE, J. (1995). Learning during anaesthesia: A review. British Journal of Psychology, 86, 479-506.

BLACHER, R. S. (1993). Psychological reactions to awareness in anesthesia. In P. S. Sebel, B. Bonke, \& E. Winograd (Eds.), Memory and awareness in anesthesia (pp. 376-386). Englewood Cliffs, NJ: Prentice-Hall.

Block, R. I., Ghoneim, M. M., Sum Ping, S. T., \& Ali, M. A. (1991). Human learning during general anaesthesia and surgery. British Journal of Anaesthesia, 66, 170-178.

BONEBAKKER, A. E. (1995). Memory during general anaesthesia: Variations in stimulus characteristics. Delft: Eburon P\&L.

Bonebakker, A. E., Bonke, B., Klein, J., Wolters, G., \& Hop, W. C. J. (1993). Implicit memory during balanced anaesthesia: Lack of evidence. Anaesthesia, 48, 657-660.

Bonke, B., Fitch, W., \& Millar, K. (Eds.). (1990). Memory and awareness in general anaesthesia. Amsterdam: Swets \& Zeitlinger.

Brown, A. S., Best, M. R., Mitchell, D. B., \& Haggard, L. C. (1992). Memory under anesthesia: Evidence for response suppression. Bulletin of the Psychonomic Society, 30, 244-246.

Browne, R. A., \& Catton, D. V. (1973). A study of awareness during anesthesia. Anesthesia \& Analgesia, 52, 128-132.

Caseley-Rondi, G., Merikle, P. M., \& Bowers, K. S. (1994). Unconscious cognition in the context of general anesthesia. Consciousness \& Cognition, 3, 166-195.

Cork, R. C., Kinlstrom, J. F., \& SChacter, D. L. (1993). Implicit and explicit memory with isoflurane compared to sufentanil/nitrous oxide. In P. S. Sebel, B. Bonke, \& E. Winograd (Eds.), Memory and awareness in anesthesia (pp. 74-80). Englewood Cliffs, NJ: Prentice-Hall.

DeBner, J. A., \& JACOBY, L. L. (1994). Unconscious perception: Attention, awareness, and control. Journal of Experimental Psychology: Learning, Memory, \& Cognition, 20, 304-317.

Dorfman, J., Kinlstrom, J. F., Cork, R. C., \& Mislaszek, J. (1995). Priming and recognition in ECT-induced amnesia. Psychonomic Bulletin \& Review, 2, 244-248.

Dubovsky, S. L., \& Trustman, R. (1976). Absence of recall after general anesthesia: Implications for theory and practice. Anesthesia \& Analgesia, 55, 696-701.

Evans, C., \& Richardson, P. H. (1988). Improved recovery and reduced postoperative stay after therapeutic suggestions during general anaesthesia. Lancet, 2, 491-493.

GhoneIM, M. M., \& Block, R. I. (1993). Learning during anesthesia. International Anesthesiology Clinics, 31, 53-65.

GRAF, P., \& MANDLER, G. (1984). Activation makes words more accessible, but not necessarily more retrievable. Journal of Verbal Learning \& Verbal Behaviour, 23, 553-568.

JACOBY, L. L. (1991). A process dissociation framework: Separating automatic from intentional uses of memory. Journal of Memory \& Language, 30, 513-541.

JaCOBY, L. L., Toth, J. P., \& Yonelinas, A. P. (1993). Separating conscious and unconscious influences of memory: Measuring recollection. Journal of Experimental Psychology: General, 122, 139-154.

Jelicic, M., Bonke, B., Wolters, G., \& Phaf, R. H. (1992). Implicit memory for words presented during anaesthesia. European Journal of Cognitive Psychology, 4, 71-80.

Jelicic, M., De Roode, A., Bovill, J. G., \& Bonke, B. (1992). Unconscious learning during anaesthesia. Anaesthesia, 47, 835-837.

Kinlstrom, J. F., \& SChacter, D. L. (1990). Anaesthesia, amnesia, and the cognitive unconscious. In B. Bonke, W. Fitch, \& K. Millar (Eds.), Memory and awareness in general anaesthesia (pp. 21-44). Amsterdam: Swets \& Zeitlinger.

Kihlstrom, J. F., Schacter, D. L., Cork, R. C., Hurt, C. A., \& Behr, S. E. (1990). Implicit and explicit memory following surgical anesthesia. Psychological Science, 1, 303-306.

MandLER, G. (1980). Recognizing: The judgment of previous occurrence. Psychological Review, 87, 252-271.

Merikle, P. M., \& Joordens, S. (1996). Measuring unconscious influences. In J. D. Cohen \& J. W. Schooler (Eds.), Scientific approaches to consciousness (pp. 109-123). Hillsdale, NJ: Erlbaum.

MillaR, K. (1992, September). Explicit and implicit memory in anaesthesia. Paper presented at the 4th Rheingau Workshop on consciousness, awareness and memory during general anaesthesia, Eltville, Germany.

MillaR, K., \& WATKINSON, N. (1983). Recognition of words presented during general anaesthesia. Ergonomics, 26, 585-594.

Munglani, R., Andrade, J., Sapsford, D. J., Baddeley, A., \& Jones, J. G. (1993). A measure of consciousness and memory during isoflu- 
rane administration: The coherent frequency. British Journal of Anaesthesia, 7, 663-641.

Parker, C. J. R., OATes, J. D. L., Boyd, A. H., \& Thomas, S. D. (1994) Memory for auditory material presented during anaesthesia. British Journal of Anaesthesia, 72, 181-184.

Roorda-Hrdlicková, V., Wolters, G., Bonke, B., \& PhaF, R. H (1990). Unconscious perception during general anaesthesia, demonstrated by an implicit memory task. In B. Bonke, W. Fitch, \& K. Millar (Eds.), Memory and awareness in general anaesthesia (pp. 150155). Amsterdam: Swets \& Zeitlinger.

Schwender, D., Kaiser, A., Klasing, S., Peter, K., \& PöPpel, E. (1994). Midlatency auditory evoked potentials and explicit and implicit memory in patients undergoing cardiac surgery. Anesthesiology, 80, 493-501.

Sebel, P. S., Bonke, B., \& Winograd, E. (EDs.). (1993). Memory and awareness in anesthesia. Englewood Cliffs, $\mathrm{NJ}$ : Prentice-Hall.

SPIElberger, C. D., Gorsuch, R. L., \& Lushene, R. E. (1970). Manual of the state-trait anxiety inventory. Palo Alto, CA: Consulting Psychologists Press.

Toth, J. P., ReINGOLD, E. M., \& JACOBY, L. L. (1994). Toward a redefinition of implicit memory: Process dissociations following elaborative processing and self-generation. Journal of Experimental Psychology: Learning, Memory, \& Cognition, 20, 290-303.
Villemure, C., Plourde, G., Lussier, I., \& Normandin, N. (1993). Auditory processing during isoflurane anesthesia: A study with an implicit memory task and auditory evoked potentials. In P. S. Sebel, B. Bonke, \& E. Winograd (Eds.), Memory and awareness in anesthesia (pp. 99-106). Englewood Cliffs, NJ: Prentice-Hall.

Winograd, E., Sebel, P. S., Goldman, W. P., \& Clifton, C. L. (1990). Indirect assessment of memory for music under anaesthesia. In B. Bonke, W. Fitch, \& K. Millar (Eds.), Memory and awareness in general anaesthesia (pp. 181-185). Amsterdam: Swets \& Zeitlinger.

\section{NOTES}

1. ASA refers to a classification of patients' physical status by the American Society of Anesthesiologists. ASA 1 refers to an otherwise normal healthy patient with a localized illness; ASA 2 refers to a patient with a mild to moderate systemic disease that does not interfere with the surgical procedure.

2. MAC (minimal alveolar concentration) is the concentration of an anesthetic at which $50 \%$ of the patients no longer respond to skin incision.

(Manuscript received May 5, 1995; revision accepted for publication December 4,1995 .) 